\section{Prevalence and risk factors for age-related macular degeneration in the elderly Chinese population in south-western Taiwan: the Puzih eye study}

EJ-C Huang ${ }^{1,2,4}$, S-H Wu'1,2,4, C-H Lai ${ }^{1,2,3}$, C-N Kuo ${ }^{1,2}$, P-L Wu ${ }^{1,2}$, C-L Chen ${ }^{1,2}$, C-Y Chen ${ }^{1,2}$, $\mathrm{Y}-\mathrm{C} \mathrm{King}^{1}$ and P-C Wu${ }^{1,2}$

\begin{abstract}
Aim This study aimed to ascertain the prevalence of and the risk factors associated with early and late age-related macular degeneration (AMD) among Chinese individuals aged $\geq 65$ years residing in Puzih, Taiwan.

Methods This population-based cross-sectional study graded digital colour photographs of the ocular fundus of 673 individuals using the Wisconsin Age-Related Maculopathy Grading System. We compared the characteristics of individuals with early and late AMD using $\chi^{2}$-analyses and described risk factors for early and late AMD using odds ratios and $\mathbf{9 5 \%}$ confidence intervals.

Results Individuals with late AMD were significantly older and more likely to have hypertension. Further, their sunlight exposure time was longer than that of those with early AMD, only drusen, or no AMD lesions $(P<0.01)$. A history of hyperlipidaemia for $>10$ years was a significant risk factor for early AMD, while old age, hypertension for $>\mathbf{1 0}$ years, and exposure to sunlight for $>8 \mathrm{~h}$ per day were associated with late AMD.

Conclusions The prevalence rate of early

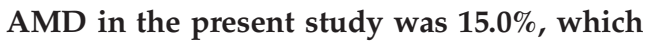
is similar to that reported for Caucasians and Japanese included in the European Eye Study and the Hisayama Study, respectively. The late AMD prevalence rate of $7.3 \%$ found among our study participants was comparable
\end{abstract}

to that reported by the Greenland Inuit Eye Study and Reykjavik Study, but considerably lower than that reported for Caucasians, indicating that late AMD might be less prevalent among Asians than Caucasians. Eye (2014) 28, 705-714; doi:10.1038/eye.2014.55; published online 14 March 2014

\section{Introduction}

Age-related macular degeneration (AMD) is the most important cause of irreversible blindness among elderly Caucasians residing in Western countries. The Beaver Dam Eye Study (1992) reported the prevalence of AMD in different racial and ethnic groups from various population-based studies, ${ }^{1}$ and, in the past decade, several reports have indicated that late AMD might be more prevalent among Caucasians living in Norway $(2.8 \%-9.5 \%)^{2-4}$ and Iceland $(5.7 \%)^{5}$ than among those living in the United States $(1.6 \%)^{1}$ and Australia (1.9\%). ${ }^{6}$ In Asia, the prevalence of late AMD is estimated to be between 0.20 and $1.90 \%$, based on data from China, 7,8 Japan, 9,10 Taiwan ${ }^{11}$ and Singapore. ${ }^{12}$ A systematic review and meta-analysis of the prevalence of AMD among Asians concluded that the prevalence of late AMD in Asians was similar to that in Caucasian populations, but that early signs of AMD were less frequently seen among Asians. ${ }^{13}$

Thus far, there have been several studies that investigated the prevalence of AMD in the Chinese population. The Beijing Eye Study
${ }^{1}$ Department of Ophthalmology, Chang Gung Memorial HospitalChiayi, Chiayi, Taiwan

${ }^{2}$ Chang Gung University College of Medicine, Tao-Yuan, Taiwan

${ }^{3}$ Department of Nursing, Chang Gung University of Science and Technology, Chiayi, Taiwan

Correspondence: C-H Lai, Department of Ophthalmology, Chang Gung Memorial Hospital Chiayi, No.6,

West Sec., Chiapu Rd., PuTzu City, Chiayi, County 613, Taiwan Tel: +88653621000 ext 2580;

Fax: +88653623002

E-mail: oph4557@ gmail.com

${ }^{4}$ These authors contributed equally to this work.

Received: 26 February 2013 Accepted in revised form: 7 February 2014 Published online: 14 March 2014 
reported a prevalence rate of 1.4 and $0.2 \%$ for early and late AMD, respectively, in Chinese people aged 40 years and older, ${ }^{8}$ whereas the Handan Eye Study in China found a prevalence rate of 3.0 and $0.1 \%$ for early and late AMD, respectively, in Chinese people aged 30 years and older. ${ }^{7}$ A multiethnic atherosclerosis study found a prevalence rate of 3.6 and $1.0 \%$ for early and late AMD, respectively, in Chinese people between 45 and 84 years of age residing in the United States, ${ }^{14}$ and the Shihpai Eye Study, conducted in Taiwan, reported a prevalence rate of 9.2 and $1.9 \%$, respectively, for early and late AMD in Chinese people aged 65 years and older. ${ }^{11}$

Puzih is a coastal city located at a latitude of $23^{\circ}$ North in south-western Taiwan. The population of Puzih is older and has a lower income and rate of eye care than the population included in the Shihpai Eye Study. Hence, the purpose of the present study was to ascertain the prevalence of and the associated risk factors for AMD among elderly Chinese individuals living in Puzih, Taiwan. To our knowledge, this is the first assessment of the prevalence of AMD among an elderly Taiwanese population since the Shihpai Eye Study (2008).

\section{Materials and methods}

\section{Statement of ethics}

The present study was conducted in accordance with the Declaration of Helsinki, and it was approved by the Institutional Review Board of Chang Gung Memorial Hospital at Chiayi, Taiwan. Written informed consent was obtained from all participants after study researchers verbally explained the procedures of the study to them. We further certify that all applicable institutional and governmental regulations concerning the ethical use of humans were followed during this research.

\section{Study population}

This was a cross-sectional population-based survey conducted from January 2010 to March 2012 in Puzih, a south-western seaside city in Chiayi County, Taiwan. Puzih has a population of 6786 individuals aged $\geq 65$ years (http://puzih-hro.cyhg.gov.tw/populB/ index.asp?Parser=99, 39). Most of Puzih residents work outdoors as farmers, fishermen, or brine evaporators.

We invited 3000 residents aged $\geq 65$ years of Puzih to participate in our study. Invitees were randomly chosen by the resident's identification number. Of the 3000 invited individuals, $708(23.6 \%)$ volunteers were enrolled. In total, 680 (96.0\%) of the study participants had at least one fundus photograph of either eye, and 673 $(95.1 \%)$ of them had gradable fundus photographs.
The mean age of our study participants suggested that the participants were young, but it was not significantly different from the mean age of the residents of Puzih recorded in the government household registration data (http:/ / puzih-hro.cyhg.gov.tw/populB/index. asp?Parser $=99$, 39) (74.2 vs 74.6 years).

\section{Procedures}

Ocular examinations included the following: (1) bestcorrected visual acuity (Snellen-chart), (2) intraocular pressure, and (3) slit-lamp testing. We took colour photographs of the fundus of participants' eyes using a fundus camera (CF-60UD, Canon Inc., Tokyo, Japan) after dilating both eyes with the administration of $0.5 \%$ tropicamide and $10 \%$ phenylephrine. In total, five $45^{\circ}$ and one $30^{\circ}$ photographs centred on the fovea were taken. We also recorded the body mass, height, waistand-hip circumference as well as the blood pressure of all our participants. Participants with hypertension and hyperlipidaemia were identified following enquiry into their medical history and use of medication, while visual function questionnaires, written in Mandarin Chinese, were completed before the performance of any examination. These questionnaires were always administered by the same research assistant.

\section{Fundus photograph grading}

All of the fundus photographs were recorded by the same research assistant and they were available in digital format. Two retinal specialists, who were blinded to data pertaining to the characteristics of participants, graded the photographs individually on a computer screen. All equivocal and late AMD lesions (geographic atrophy and neovascular AMD) were discussed among the specialists, and they graded each of the fundus photographs according to the Wisconsin Age-Related Maculopathy Grading System. ${ }^{15}$ Drusen size $(<63 \mu \mathrm{m}$, 63-125 $\mu \mathrm{m},>125 \mu \mathrm{m},>500 \mu \mathrm{m}$ ), type (distinct or indistinct), number and area (defined using the diameter with the centre of the macula as Zone $1(1000 \mu \mathrm{m})$, Zone $2(3000 \mu \mathrm{m})$, or Zone $3(6000 \mu \mathrm{m}))$ were recorded. Hyper- and hypopigmentation of the retinal pigment epithelium, geographic atrophy, and signs of exudative macular degeneration (serous retinal detachment, subretinal haemorrhage, subretinal fibrous scar, retinal pigment epithelial detachment, or laser scar for the treatment of exudative AMD) were recorded. If lesion types differed between the left and right eyes, then the more severe lesion was used for statistical analysis.

If the fundus photographs of participants with late AMD were indistinguishable from those indicative of chronic central serous chorioretinopathy (CSCR), 
polypoidal choroidal vasculopathy (PCV), or other diseases, participants underwent fluorescein angiography (FAG) plus indocyanine green angiography (ICG) to exclude chronic CSCR, PCV, or other diseases.

\section{Definition for early and late AMD}

Early AMD was defined, in accordance with the guidelines used in the Blue Mountain Eye Study: the presence of soft, indistinct, or reticular drusen or that of soft, distinct, drusen plus retinal pigment epithelium abnormalities. Late AMD was defined as either geographic atrophy or neovascular AMD.

\section{Risk factors}

Age was defined as the age at the time of examination.

Smoking history was ascertained by asking participants whether they were past, current, or non-smokers. Current smokers were defined as participants who smoked more than 20 cigarettes at the time of the study or in the 6 months before the study. Past smokers were considered as those participants who relinquished smoking for at least 6 months, and non-smokers were considered as those who had never smoked.

Current alcohol drinkers in our study were defined as those individuals who, at the time of the study, had consumed alcohol on more than 184 days in the year before the study.

Hypertensive individuals were considered those who were using antihypertensive medication as well as those with a previous diagnosis or self-reported history or a recorded systemic blood pressure (SBP) of $>140 \mathrm{~mm} \mathrm{Hg}$ and diastolic blood pressure (DBP) of $>90 \mathrm{~mm} \mathrm{Hg}$. Further, the duration of hypertension was categorized as longer or shorter than 10 years based on the medical history and anti-hypertensive medication usage of participants.

Diabetic individuals were identified based on the medical history of participants and the use of antihyperglycaemia agents. The duration of diabetes was also recorded as either longer or shorter than 10 years.

Hyperlipidaemia was assessed according to the medical history of antihyperlipidaemia agents. The duration of diabetes was also recorded as either longer or shorter than 10 years.

We assessed sunlight exposure by asking participants regarding the number of hours in a day during which they were exposed to sunlight in their lifetime $(<4 \mathrm{~h}, 4-8 \mathrm{~h}$, or $>8 \mathrm{~h})$.

\section{Statistical analysis}

Statistical analyses were conducted using the Statistical Package for Social Sciences for Windows (version 12.0, SPSS Inc., Chicago, IL, USA). $\chi^{2}$-analyses were used to analyse demographic data, prevalence of the drusen type, pigmentary changes, and early or late AMD related to age and sex. Odds ratios (ORs) and 95\% confidence intervals (CIs) were determined for risk factors related to early or late AMD. Statistical significance was set at $P<0.05$. Age-standardized prevalence was estimated using direct standardization of the study samples to the world population in 2000 (http://seer.cancer.gov/ stdpopulations/world.who.html).

\section{Results}

Of the 708 participants included in the present study, $680(96.04 \%)$ had at least one fundus photograph of either eye, and 673 (95.05\%) had gradable fundus photographs. Among these 673 participants, the average age was 74.14 years; 365 (54.2\%) were men, and 308 (45.8\%) were women There was no statistically significant difference between participants with and without gradable photographs with regard to age, gender, education level, proportion with diabetes, or hypertension.

\section{Demographic characteristics of participants according to the lesion type}

Gender, body mass index (BMI), waist-to-hip ratio, education level, alcohol consumption, smoking habits, and the incidence of diabetes and hyperlipidaemia did not differ significantly between participants with no AMD lesions, drusen only, early AMD, or late AMD. Participants with late AMD were significantly older, their average duration of daily sun exposure was significantly longer, and they were significantly more likely to suffer from hypertension than participants with early AMD, with drusen only, or with no AMD lesions $(P<0.01$, Table 1).

\section{Prevalence of drusen, pigmentary changes, and early and late $A M D$}

The prevalence of soft drusen (drusen $>63 \mu \mathrm{m}$, including distinct and indistinct drusen) among all participants was $40.6 \%(n=273)$. Significantly more men than women had soft drusen (43.3 vs $37.3 \%$, Table 2). Older participants were significantly more likely to have a drusen area of $>500 \mu \mathrm{m}(P=0.040$, Table 2$)$. Pigmentary changes were significantly associated with older age ( $P=0.040$ for men, $P=0.013$ for women, and $P=0.040$ 
Table 1 Demographic characteristics by no lesion, drusen only, early AMD, and late AMD in the Puzih eye study, Taiwan, 2010-2012

\begin{tabular}{|c|c|c|c|c|}
\hline \multirow[t]{2}{*}{ Charateristics } & $\begin{array}{l}\text { No lesion } \\
(\mathrm{n}=358)\end{array}$ & $\begin{array}{l}\text { Drusen only } \\
(\mathrm{n}=165)\end{array}$ & $\begin{array}{c}\text { Early } A M D \\
(\mathrm{n}=101)\end{array}$ & $\begin{array}{l}\text { Late AMD } \\
\quad(\mathrm{n}=49)\end{array}$ \\
\hline & \multicolumn{4}{|c|}{ Mean (SD) } \\
\hline Male $(\%)$ & $189(52.8)$ & $96(58.2)$ & $58(57.4)$ & $22(44.9)$ \\
\hline Age $(\text { years) })^{* *}$ & $73.72(6.04)$ & $73.52(6.07)$ & $74.53(6.36)$ & 77. $18(6.02)$ \\
\hline Body mass index (BMI) & $24.54(3.24)$ & $24.15(3.32)$ & $24.82(3.70)$ & $24.68(3.98)$ \\
\hline Waist-hip ratio (WH ratio) & $0.90(0.07)$ & $0.89(0.07)$ & $0.89(0.07)$ & $0.89(0.07)$ \\
\hline High school or higher education (\%) & $71(19.9)$ & 39 (23.6) & 21(20.8) & 7 (14.3) \\
\hline Alcohol $(\%)$ & $39(10.9)$ & $13(7.9)$ & $9(8.9)$ & $4(8.2)$ \\
\hline Smoke $(\%)$ & $90(25.3)$ & $49(29.7)$ & $29(28.7)$ & $11(22.4)$ \\
\hline Hypertension $(\%)^{*}$ & $186(52.0)$ & $76(46.1)$ & $55(54.5)$ & $34(69.4)$ \\
\hline Less than 10 years $(\%)^{* *}$ & $111(31.0)$ & $45(27.3)$ & $35(34.7)$ & $12(24.5)$ \\
\hline 10 or more than 10 years $(\%)^{* *}$ & 75 (20.9) & $31(18.8)$ & $20(19.8)$ & $22(44.9)$ \\
\hline Diabetes $(\%)$ & $119(33.2)$ & $47(28.5)$ & $31(30.7)$ & $17(34.7)$ \\
\hline Less than 10 years $(\%)$ & $60(16.8)$ & $23(13.9)$ & $17(16.8)$ & $7(14.3)$ \\
\hline 10 or more than 10 years $(\%)$ & $59(16.5)$ & $24(14.5)$ & $14(13.9)$ & $10(20.4)$ \\
\hline Hyperlipidemia (\%) & $51(14.2)$ & $24(14.5)$ & $25(24.8)$ & $8(16.3)$ \\
\hline Less than 10 years $(\%)$ & $38(10.6)$ & 19 (11.5) & $17(16.8)$ & $7(14.3)$ \\
\hline 10 or more than 10 years $(\%)$ & $13(3.6)$ & $5(3.0)$ & $8(7.9)$ & $1(2.0)$ \\
\hline \multicolumn{5}{|l|}{ Sunlight Exposure ${ }^{* *}$} \\
\hline$<4 \mathrm{~h}$ per day $(\%)$ & $187(52.4)$ & $86(52.1)$ & $49(48.5)$ & $13(26.5)$ \\
\hline $4-8 \mathrm{~h}$ per day $(\%)$ & $62(17.4)$ & $15(9.1)$ & $18(17.8)$ & 7 (14.3) \\
\hline$>8 \mathrm{~h}$ per day $(\%)$ & $108(30.3)$ & $64(38.8)$ & $34(33.7)$ & $29(59.2)$ \\
\hline
\end{tabular}

Abbreviation: AMD, age-related macular degeneration. Values are mean $( \pm \mathrm{SD})$ or numbers (percentages). ${ }^{*} P<0.05 ;{ }^{* *} P<0.01$.

Table 2 Prevalence of early AMD lesions and early and late AMD by sex and age in the Puzih eye study

\begin{tabular}{|c|c|c|c|c|c|c|}
\hline Age group (years) & Risk number & $\begin{array}{l}\text { Soft drusen } \\
\mathrm{n}(\%)\end{array}$ & $\begin{array}{c}\text { Drusen area }>500 \mu \mathrm{m} \\
\mathrm{n}(\%)\end{array}$ & $\begin{array}{c}\text { Pigment abnormalities } \\
\mathrm{n}(\%)\end{array}$ & $\begin{array}{c}\text { Early } A M D \\
\mathrm{n}(\%)\end{array}$ & $\begin{array}{l}\text { Late } A M D \\
\mathrm{n}(\%)\end{array}$ \\
\hline \multicolumn{7}{|l|}{ Men } \\
\hline $65-69$ & 103 & 50 (48.5) & $1(1.0)$ & $4(3.9)$ & 17 (16.5) & $3(2.9)$ \\
\hline 70-74 & 96 & $41(42.7)$ & $2(2.1)$ & $3(3.1)$ & $18(18.8)$ & $3(3.1)$ \\
\hline 75-79 & 78 & 30 (38.5) & $5(6.4)$ & 9 (11.5) & 9 (11.5) & $8(10.3)$ \\
\hline$\geq 80$ & 88 & $37(42.0)$ & $3(3.4)$ & $8(9.1)$ & $14(15.9)$ & $8(9.1)$ \\
\hline Total & 365 & $158(43.3)$ & $11(3.0)$ & $24(6.6)$ & $58(15.9)$ & $22(6.0)$ \\
\hline$P$-value ${ }^{\mathrm{a}}$ & & 0.291 & 0.142 & $0.040^{* *}$ & 0.615 & $0.021^{* *}$ \\
\hline \multicolumn{7}{|l|}{ Women } \\
\hline $65-69$ & 86 & $29(33.7)$ & $1(1.2)$ & $2(2.3)$ & $9(10.5)$ & $4(4.7)$ \\
\hline $70-74$ & 84 & $30(35.7)$ & $1(1.2)$ & $3(3.6)$ & $10(11.9)$ & $3(3.6)$ \\
\hline $75-79$ & 60 & $25(41.7)$ & $3(5.0)$ & $6(10.0)$ & $10(16.7)$ & $9(15.0)$ \\
\hline$\geq 80$ & 78 & $31(39.7)$ & $3(3.8)$ & $8(10.3)$ & $14(17.9)$ & $11(14.1)$ \\
\hline Total & 308 & $115(37.3)$ & $8(2.6)$ & $19(6.2)$ & $43(14.0)$ & $27(8.8)$ \\
\hline$P$-value ${ }^{\mathrm{a}}$ & & 0.331 & 0.148 & $0.013^{* *}$ & 0.120 & $0.006^{* * *}$ \\
\hline \multicolumn{7}{|l|}{ Both genders } \\
\hline $65-69$ & 189 & $79(41.8)$ & $2(1.1)$ & $6(3.2)$ & $26(13.8)$ & $7(3.7)$ \\
\hline $70-74$ & 180 & $71(39.4)$ & $3(1.7)$ & $6(3.3)$ & $28(15.6)$ & $6(3.3)$ \\
\hline $75-79$ & 138 & $55(39.9)$ & $8(5.8)$ & $15(10.9)$ & $19(13.8)$ & $17(12.3)$ \\
\hline$\geq 80$ & 166 & $68(41.0)$ & $6(3.6)$ & $16(9.6)$ & $28(16.9)$ & 19 (11.4) \\
\hline Total & 673 & $273(40.6)$ & $19(2.8)$ & $43(6.4)$ & $101(15.0)$ & $49(7.3)$ \\
\hline$P$-value ${ }^{\mathrm{a}}$ & & 0.891 & $0.040^{* *}$ & $0.001^{* * *}$ & 0.518 & $<0.001^{* * *}$ \\
\hline
\end{tabular}

Abbreviation: AMD, age-related macular degeneration. ${ }^{* *} P$-value $<0.05$; ${ }^{* * *} P$-value $<0.01$.

${ }^{a} \chi^{2}$-trend test for age groups.

for the total group). The prevalence of pigmentary changes was similar in men and women (6.6 and 6.2\%, respectively, Table 2 ).

The overall prevalence of late AMD was $7.3 \%(n=49)$ and it increased significantly with age $(P=0.021$ for men,
$P=0.006$ for women; and $P<0.001$ for the total group, Table 2). The prevalence of early AMD was higher in men than in women (15.9 vs $14.0 \%$, respectively), but the prevalence of late AMD was higher in women than in men (8.8 vs $6.0 \%$, respectively, Table 2 ). 
Table 3 Multivariate regression analysis of risk factors associated with early and late AMD

\begin{tabular}{|c|c|c|c|c|}
\hline \multirow[t]{2}{*}{ Risk factors } & \multicolumn{2}{|l|}{ Early $A M D$} & \multicolumn{2}{|l|}{ Late AMD } \\
\hline & Adjusted odds ratio (95\% CI) & P-value & Adjusted odds ratio (95\% CI) & P-value \\
\hline Age (vs 65-69) & & 0.834 & & $0.004^{* *}$ \\
\hline $70-74$ & $1.165(0.645-2.105)$ & 0.613 & $0.593(0.179-1.961)$ & 0.392 \\
\hline $75-79$ & $1.067(0.555-2.051)$ & 0.847 & $2.746(1.062-7.100)$ & $0.037^{*}$ \\
\hline$\geq 80$ & $1.308(0.721-2.374)$ & 0.376 & $2.993(1.179-7.601)$ & $0.021^{*}$ \\
\hline Sex (Male vs Female) & $1.173(0.697-1.974)$ & 0.549 & $0.734(0.339-1.586)$ & 0.431 \\
\hline Smoking (vs non-smokers) & & 0.779 & & 0.936 \\
\hline Past smokers & $1.047(0.548-2.001)$ & 0.890 & $0.997(0.349-2.846)$ & 0.995 \\
\hline Current smokers & $1.369(0.565-3.319)$ & 0.487 & $1.282(0.302-5.450)$ & 0.737 \\
\hline Alcohol (current drinkers vs none) & $0.727(0.316-1.672)$ & 0.453 & $0.807(0.223-2.924)$ & 0.745 \\
\hline Body mass index (vs $\left.<24 \mathrm{~kg} / \mathrm{m}^{2}\right)$ & & 0.537 & & 0.498 \\
\hline $24-26.99$ & $0.996(0.599-1.658)$ & 0.988 & $0.661(0.305-1.429)$ & 0.292 \\
\hline $27+$ & $1.335(0.766-2.325)$ & 0.308 & $1.043(0.474-2.296)$ & 0.916 \\
\hline Diabetes (vs none) & & 0.832 & & 0.989 \\
\hline Less than 10 years & $0.939(0.509-1.735)$ & 0.842 & $0.981(0.386-2.496)$ & 0.968 \\
\hline 10 or more than 10 years & $0.819(0.427-1.571)$ & 0.549 & $0.938(0.396-2.221)$ & 0.884 \\
\hline Hypertension (vs none) & & 0.534 & & $<0.001^{* *}$ \\
\hline Less than 10 years & $1.243(0.756-2.042)$ & 0.392 & $1.205(0.526-2.758)$ & 0.660 \\
\hline 10 or more than 10 years & $0.885(0.479-1.634)$ & 0.696 & $4.529(2.029-10.111)$ & $<0.001^{* *}$ \\
\hline Hyperlipidemia (vs none) & & $0.019^{*}$ & & 0.653 \\
\hline Less than 10 years & $1.720(0.937-3.159)$ & 0.080 & $1.113(0.451-2.848)$ & 0.791 \\
\hline 10 or more than 10 years & $3.022(1.227-7.446)$ & $0.016^{*}$ & $0.393(0.047-3.264)$ & 0.387 \\
\hline Sunlight exposure (vs. <4 hours per day) & 0.707 & & $0.003^{* *}$ & \\
\hline 4-8 hours per day & $1.238(0.674-2.273)$ & 0.492 & $1.950(0.726-5.238)$ & 0.185 \\
\hline$>8$ hours per day & $0.947(0.578-1.551)$ & 0.829 & $3.497(1.683-7.268)$ & $0.001^{* *}$ \\
\hline
\end{tabular}

Abbreviation: AMD, age-related macular degeneration. ${ }^{*} P$-value $<0.05{ }^{* *} P$-value $<0.01$.

\section{Risk factors for early and late AMD}

Early AMD Hyperlipidaemia for a period of more than 10 years was the only statistically significant risk factor for early AMD (OR=3.022, $P=0.016$, Table 3).

Late AMD After multivariate adjustment, age was found to be a significant factor associated with late AMD ( $P=0.004$, Table 3$)$.

The OR for participants developing late AMD at the age of 70-74, 75-79, and $\geq 80$ years was $0.593,2.746$, and 2.993 when compared with participants aged 65-69 years.

Participants with hypertension for a period of more than 10 years had a higher risk for developing late AMD than those with hypertension for less than 10 years $(\mathrm{OR}=4.529$; $P<0.001)$ People exposed to sunlight for $4-8 \mathrm{~h}$ per day and $>8 \mathrm{~h}$ a day had a significantly higher risk of developing late AMD than those exposed to sunlight for $<4 \mathrm{~h}$ per day $(P=0.185$ and $P=0.001$, respectively). Gender, smoking habit, alcohol consumption, BMI, and diabetes were not significantly associated with early or late AMD.

\section{Discussion}

The prevalence of early AMD found in the present study was similar to that reported for Caucasians in the European Eye Study (EUREYE) ${ }^{16}$ and for Asian Japanese in the Hisayama Study. ${ }^{17}$ The prevalence of late AMD in our study $(7.3 \%)$ was higher than that reported in any previous study conducted anywhere else in the world (Table 4). However, after age standardization of participants aged $\geq 65$ according to the world population in the year 2000, the prevalence of early AMD (14.8\%) more closely reflected the results of EUREYE (14.86\%) and the Hisayama Study (14.62\%), while the prevalence of late AMD $(6.62 \%)$ was similar to that reported in EUREYE (6.62\%, Table 4).

We have summarized the prevalence rates of AMD among Chinese populations using data from studies that followed the Wisconsin Age-Related Maculopathy Grading System after age-standardized prevalence of participants aged $\geq 65$ (except the Handan Eye Study that was conducted in individuals aged $\geq 60$ years) (Figure 1).7,8,11,14 The Puzih Eye Study has, thus far, reported the highest prevalence of early and late AMD among Chinese individuals. $7,8,11,14$

To our knowledge, we were the first to investigate the prevalence of AMD in Taiwan since the Shihpai Eye Study (2008). ${ }^{11}$ Shihpai is located in Taipei, the capital of Taiwan, and residents of the Shihpai area have, in general, a higher socio-economic status and a higher level of education (http://www.bthr.taipei.gov.tw/ public/Attachment/231610461872.pdf; http:/ / puzih-hro. cyhg.gov.tw/populD/index.asp?Parser=99, 41); further, they receive more eye care than residents of Puzih. Puzih, 
Table 4 Summary of early and late AMD prevalence in population-based studies since 1992

\begin{tabular}{|c|c|c|c|c|c|c|}
\hline & & Year & Participants & Age & $\begin{array}{c}\text { Early AMD } \\
\text { (age standarization }{ }^{\mathrm{a}} \text { ) }\end{array}$ & $\begin{array}{c}\text { Late AMD } \\
\text { (age standarization }{ }^{\text {a }} \text { ) }\end{array}$ \\
\hline USA & The Beaver Dam Eye Study & 1992 & 4926 & $43-86$ & $15.6 \%(21.74 \%)$ & $1.6 \%(3.22 \%)$ \\
\hline Australia & The Blue Mountains Eye Study & 1995 & 3405 & $\geq 49$ & $7.2 \%(11.7 \%)$ & $1.9 \%(3.27 \%)$ \\
\hline Netherlands & The Rotterdam Study & 1995 & 6251 & 55-98 & & $1.7 \%(2.44 \%)$ \\
\hline USA & The Baltimore Eye Survey & 1999 & $\begin{array}{l}\text { Blacks } 1843 \\
\text { Whites } 2518\end{array}$ & $\begin{array}{l}40-80+ \\
40-86\end{array}$ & & $\begin{array}{l}0.22 \%(0.24 \%) \\
1.23 \%(2.15 \%)\end{array}$ \\
\hline Japan & The Hisayama study & 2001 & 1486 & $\geq 50$ & $12.6 \%(14.62 \%)$ & $0.87 \%(1.11 \%)$ \\
\hline USA & The Los Angeles Latino Eye Study & 2004 & 5875 & $\geq 40$ & $9.4 \%(15.79 \%)$ & $0.43 \%(1.71 \%)$ \\
\hline Europe & The European Eye Study & 2006 & 4753 & $\geq 65$ & $12.6 \%(14.86 \%)$ & $3.32 \%(6.62 \%)$ \\
\hline China & The Beijing Eye Study & 2006 & 4439 & $\geq 40$ & $1.4 \%(2.82 \%)$ & $0.2 \%(0.41 \%)$ \\
\hline Norway & The Oslo macular study & 2006 & 459 & $\geq 51$ & $43.10 \%$ & $2.80 \%$ \\
\hline Japan & The Funagata Study & 2008 & 1625 & $\geq 35$ & $3.5 \%$ & $0.5 \%$ \\
\hline Singapore & The Singapore Malay Eye Study & 2008 & 3265 & $40-80$ & $3.5 \%(7.71 \%)$ & $0.34 \%(1.25 \%)$ \\
\hline Taiwan & The Shihpai Eye Study & 2008 & 1058 & $\geq 65$ & $9.2 \%(11.8 \%)$ & $1.9 \%(2.87 \%)$ \\
\hline Norway & The Greenland Inuit Eye Study & 2008 & 695 & $\geq 60$ & & $9.5 \%(12.33 \%)$ \\
\hline Iceland & The Reykjavik Study & 2011 & 5272 & $\geq 66$ & $21.3 \%(17.75 \%)$ & $\begin{array}{c}5.7 \%(4.21 \%) \\
(30.8 \% \geq 80 \text { years })\end{array}$ \\
\hline China & The Handan Eye Study & 2011 & $\begin{array}{l}4049 \\
6581\end{array}$ & $\begin{array}{l}\geq 50 \\
\geq 30\end{array}$ & $\begin{array}{c}4.7 \%(5.54 \%) \\
3.00 \%\end{array}$ & $\begin{array}{c}0.2 \%(0.23 \%) \\
0.10 \%\end{array}$ \\
\hline Norway & The Tromso Eye Study & 2012 & 2631 & $65-87$ & & $3.5 \%(3.83 \%)$ \\
\hline Taiwan & The Puzih Eye Study & 2012 & 673 & $\geq 65$ & $15 \%(14.8 \%)$ & $7.3 \%(6.62 \%)$ \\
\hline
\end{tabular}

Abbreviation: AMD, age-related macular degeneration.

${ }^{a}$ Age-standardized prevalence of early and late AMD according to the 2000 year world population in different populations of participants aged $>65$ years (except the Handan eye study was aged $>60$ years).

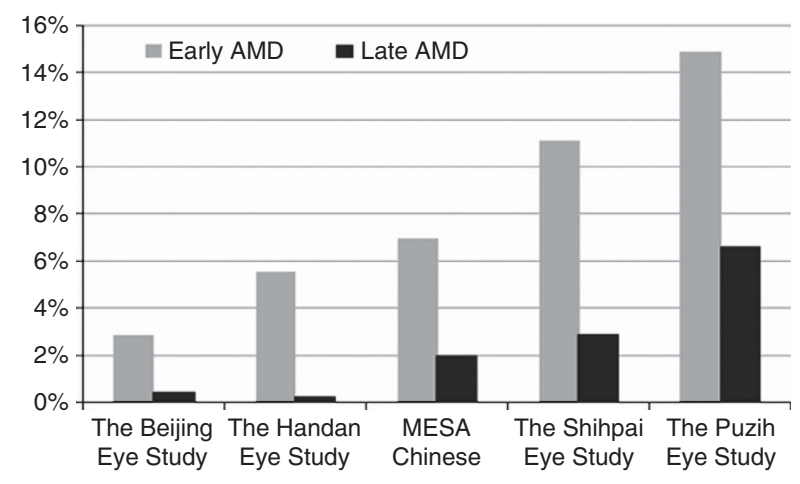

Figure 1 After age standardization prevalence of participants aged 65 or more (except the Handan eye study participants aged 60 or more) in major Chinese population-based studies where AMD lesions were assessed following the Wisconsin AgeRelated Maculopathy Grading System. AMD, age-related macular degeneration.

in turn, is located in Chiayi County, a region that has the highest ageing index in Taiwan (http://

www.dgbas.gov.tw/public/data/dgbas04/bc6/ census002(final).html) and where there were no large medical institutions until 10 years ago. Most residents of Puzih work outdoors every day as farmers, fishermen, or brine evaporators.

The age-standardized prevalence of both early and late AMD in our study was higher than that reported in the Shihpai Study (14.8 vs $11.8 \%$ and 6.6 vs $2.87 \%$, respectively, Table 4). Both our study and the Shihpai
Study included Chinese individuals aged $\geq 65$ years, and the difference in the prevalence of late AMD between the two studies may well be due to differences in the occupations $^{18}$ and eye care ${ }^{19}$ of individuals in Puzih and Shihpai. These factors may affect the development of late AMD.

The Beaver Dam Eye Study, ${ }^{1}$ the Blue Mountains Eye Study (BMES), ${ }^{6}$ and the Rotterdam Study ${ }^{20}$ reported a prevalence rate of 1.6-1.9\% for late AMD among Caucasians. Considering the results of the Hisayama Study, ${ }^{10}$ the Funagata Study ${ }^{9}$ the Singapore Malay Eye Study, ${ }^{21}$ and the Handan Eye Study, ${ }^{7}$ late AMD seems to be less common among Asians than among Caucasians. The Baltimore Eye Survey reported that late AMD is more common among Asians than among African Americans. ${ }^{22}$ Three studies conducted in Norway (the Oslo Macular Study, ${ }^{2}$ the Greenland Inuit Eye Study, ${ }^{3}$ and the Tromso Eye Study ${ }^{4}$ ) reported a higher prevalence of late AMD (2.8-9.5\%) compared with other studies conducted among Caucasians. In contrast, the Reykjavik Study ${ }^{5}$ in Iceland, which included participants living above the arctic circle, found that the prevalence of late AMD was $9.5 \%$ among participants aged $\geq 60$ years and $30.8 \%$ among those aged $\geq 80$ years.

The prevalence of late AMD in our study (7.3\%) is more consistent with data from individuals residing in Nordic countries than with data from studies conducted among Asians. We suggest that exposure to sunlight could contribute to the development of $\mathrm{AMD}^{4,23-25}$ and that the 
extent of sunlight exposure provides a reasonable explanation for the higher prevalence of late AMD in Nordic regions. Puzih is located at $23^{\circ}$ North, which is far south of the Nordic regions, and, unlike the Nordic regions, sunlight in Puzih does not have seasonal daylight variations. Nevertheless, most participants in the Puzih Eye Study work outdoors all day, and they are thus exposed to long hours of sunlight since their 20s. Visible blue light in sunlight induces photochemical or photo-oxidative damage to the retinal pigment epithelium, and this may lead to the development of AMD. ${ }^{26-28}$ Although other factors, such as dietary habits, might also explain the high prevalence of late AMD among residents of Puzih, we suggest that exposure to sunlight is a crucial factor contributing to the pathogenesis of AMD.

According to AREDS (Age-Related Eye Disease Study) and other studies, ${ }^{29-32}$ dietary intake of zinc and antioxidants plus zinc can, in high-risk groups, reduce the risks of developing advanced AMD by $25 \%$. Early intervention strategies are thus clearly important for the prevention of late AMD. In Puzih, the introduction of intervention strategies has, until recently, not been possible because the city did not have a large medical institute until 10 years ago. In elderly individuals, AMD can be mistaken for cataracts, especially when adequate eye care is unavailable. Even when AMD is diagnosed early, a lack of education and the high cost associated with the long-term use of antioxidants and zinc can lead to AMD being neglected by elderly individuals.

In our study, advanced age, hypertension for more than 10 years, and exposure to sunlight were associated with late AMD, while hyperlipidaemia for more than 10 years was associated with early AMD. Other characteristics such as a female gender, the amount of alcohol consumed, the presence of diabetes mellitus, and an increased BMI were not significantly associated with AMD.

Several previous studies have reported hypertension as a risk factor for AMD. ${ }^{33-35}$ We found that hypertension for more than 10 years, with or without pharmacologic control, was significantly associated with the development of late AMD $(\mathrm{OR}=4.592 ; P<0.001)$. This observation is consistent with conclusions of the Framingham Study: the prevalence of age-related maculopathy progressively increases with an increase in the duration of systemic hypertension. ${ }^{36}$ The pathogenic mechanism of AMD has not yet been elucidated, but prolonged filling of choroidal capillaries and thickening of Bruch's membranes can be seen in patients with AMD. ${ }^{37}$ These observations suggest that long-standing hypertension can, through atherosclerotic changes, affect choroidal blood flow, which, in turn, can increase the risk for the development of AMD. ${ }^{38}$
Exposure to intense bright sunlight or ultraviolet radiation may cause changes in the retinal pigment epithelium, leading to the pathogenic changes observed in AMD. Several studies have, thus far, reported that exposure to sunlight might increase the risk of AMD. ${ }^{4,23-25}$ In our study, participants who were exposed to sunlight for $4-8 \mathrm{~h}$ or for $>8 \mathrm{~h}$ per day had a significantly greater risk for the development of late AMD than those exposed to sunlight for $<4 \mathrm{~h}$ per day $(\mathrm{OR}=1.670$ and 1.746 , respectively, and $P=0.040$ and $P=0.004$, respectively). Although it is not possible to establish causality between sunlight exposure and late AMD, it is good practice to educate patients on the measures that they should take to prevent eye damage due to sunlight exposure, such as the wearing of hats and sunglasses. ${ }^{39}$

A habit of smoking cigarettes has been identified as a risk factor for AMD in women ${ }^{40}$ in Caucasians, ${ }^{34,41,42}$ and the Japanese. ${ }^{9}$ However, in our study, a current habit of smoking or previous smoking was not associated with AMD. Our finding is consistent with the results of studies conducted in Beijing ${ }^{43}$ and Shihpai. ${ }^{11}$

Hyperlipidaemia is associated with atherosclerosis and cardiovascular disease, and studies have indicated a relationship between cardiovascular disease and AMD. However, hyperlipidaemia has not been indicated as an independent risk factor for AMD in previous studies. ${ }^{43,44}$ We found that hyperlipidaemia for more than 10 years was associated with the development of early but not with late $\mathrm{AMD}(\mathrm{OR}=3.022, P=0.016)$. In addition, the use of HMG CoA reductase inhibitors (statins), which reduce lipid levels and act as anti-inflammatory agents, is reported to be inversely associated with AMD. ${ }^{45,46}$ Patients who use statins to treat hyperlipidaemia might thus prevent the progression of early to late AMD. Further studies to elucidate possible mechanisms whereby statins could interrupt processes leading to AMD are needed.

Our study had several limitations. First, the sample size of our study was small compared with that of other studies. Further, our study cohort represented only $10 \%$ (680/6807) of the entire elderly population of Puzih. Second, there was a potential for selection bias because all of our participants were volunteers. Third, grading of the fundus photographs without fluorescein angiography and optical coherence tomography performed in conjunction may have led to misclassification of participants. For example, myopic maculopathy exhibits fundus features similar to those of exudative AMD, and these conditions have a higher prevalence among the Chinese ${ }^{47,48}$ than among other populations. Fourth, the ages of participants and the definition of early AMD differ between studies, which complicate direct comparisons of the prevalence of early 
and late AMD between populations and regions. Fifth, in our study, sunlight exposure time was strongly associated with late AMD, but evidence of self-reported sunlight exposure time was not strong. Strengths of the present study include its population-based design, the high-response rate $(95 \%)$, and use of standardized protocols from the Wisconsin AMD Grading System ${ }^{15}$ and BMES. ${ }^{6}$

In summary, our study demonstrated that the prevalence of early AMD in Puzih people was similar to that observed in Caucasians reported in EUREYE and in the Japanese reported in the Hisayama Study. The observed prevalence of late AMD in our study (7.3\%) was similar to that in the Greenland Inuit Eye Study and The Reykjavik Study, but it was considerably higher than that in previous reports regarding the prevalence of AMD among Asians as well as Caucasians. We found that hyperlipidaemia for more than 10 years was associated with the development of early AMD. Older age, hypertension for more than 10 years, and exposure to sunlight were associated with the development of late AMD. The results of this study indicate that AMD might be prevented through the control of hypertension and hyperlipidaemia, and the avoidance of excessive exposure to sunlight.

\section{Summary}

\section{What was known before}

- Several studies have been conducted on the prevalence of AMD in the Chinese population.

- The Beijing Eye Study in China reported that the prevalence of early and late AMD in Chinese people aged 40 years or more is $1.4 \%$ and $0.2 \%$, respectively.

- The Handan Eye Study in China concluded that the prevalence of early and late AMD in Chinese people aged 30 years or more is $3.0 \%$ and $0.1 \%$, respectively.

- The Multiethnic Study of Atherosclerosis Study reported that the prevalence of early and late AMD in Chinese people aged 45 to 84 years living in the United States is $3.6 \%$ and $1.0 \%$, respectively.

- The Shihpai Eye Study in Taiwan concluded that the prevalence of early and late AMD in Chinese people aged 65 years or more is $9.2 \%$ and $1.9 \%$, respectively.

What this study adds

- The prevalence rate of early AMD in the present study was $15.0 \%$, which is similar to that reported for Caucasians and Japanese reported in the European Eye Study and the Hisayama Study, respectively.

- The late AMD prevalence rate of $7.3 \%$ found among our study participants was comparable to that reported by the Greenland Inuit Eye Study and Reykjavik Study, but considerably lower than that reported for Caucasians, indicating that late AMD might be less prevalent among Asians than Caucasians.

\section{Conflict of interest}

The authors declare no conflict of interest.

\section{Acknowledgements}

This study was supported by a grant from the Chang Gung Memorial Hospital, ROC: CMRP680341, CMRP680342.

\section{Disclaimer}

The sponsors had no role in the study design, acquisition of data, statistical analysis and interpretation, and the final presentation and publication of the study.

\section{References}

1 Klein R, Klein BE, Linton KL. Prevalence of age-related maculopathy. The Beaver Dam Eye Study. Ophthalmology 1992; 99(6): 933-943.

2 Bjornsson OM, Syrdalen P, Bird AC, Peto T, Kinge B. The prevalence of age-related maculopathy (ARM) in an urban Norwegian population: the Oslo Macular Study. Acta Ophthalmol Scand 2006; 84(5): 636-641.

3 Andersen MV, Rosenberg T, la Cour M, Kiilgaard JF, Prause JU, Alsbirk PH et al. Prevalence of age-related maculopathy and age-related macular degeneration among the inuit in Greenland. The Greenland Inuit Eye Study. Ophthalmology 2008; 115(4): 700-7 e1.

4 Erke MG, Bertelsen G, Peto T, Sjolie AK, Lindekleiv H, Njolstad I. Prevalence of age-related macular degeneration in elderly Caucasians: The Tromso Eye Study. Ophthalmology 2012; 119(9): 1737-1743.

5 Jonasson F, Arnarsson A, Eiriksdottir G, Harris TB, Launer LJ, Meuer SM et al. Prevalence of age-related macular degeneration in old persons: age, gene/ environment susceptibility: Reykjavik Study. Ophthalmology 2011; 118(5): 825-830.

6 Mitchell P, Smith W, Attebo K, Wang JJ. Prevalence of age-related maculopathy in Australia: The Blue Mountains Eye Study. Ophthalmology 1995; 102(10): 1450-1460.

7 Yang K, Liang YB, Gao LQ, Peng Y, Shen R, Duan XR et al. Prevalence of age-related macular degeneration in a rural Chinese population: the Handan Eye Study. Ophthalmology 2011; 118(7): 1395-1401.

8 Li Y, Xu L, Jonas JB, Yang H, Ma Y, Li J. Prevalence of age-related maculopathy in the adult population in China: the Beijing eye study. Am J Ophthalmol 2006; 142(5): 788-793.

9 Kawasaki R, Wang JJ, Ji GJ, Taylor B, Oizumi T, Daimon $\mathrm{M}$ et al. Prevalence and risk factors for age-related macular degeneration in an adult Japanese population: the Funagata study. Ophthalmology 2008; 115(8): 1376-1381, 81 e1-2.

10 Oshima Y, Ishibashi T, Murata T, Tahara Y, Kiyohara Y, Kubota T. Prevalence of age related maculopathy in a representative Japanese population: the Hisayama study. Br J Ophthalmol 2001; 85(10): 1153-1157.

11 Chen SJ, Cheng CY, Peng KL, Li AF, Hsu WM, Liu JH et al. Prevalence and associated risk factors of age-related macular degeneration in an elderly Chinese population in 
Taiwan: the Shihpai Eye Study. Investig Ophthalmol Vis Sci 2008; 49(7): 3126-3133.

12 Kawasaki R, Wang JJ, Aung T, Tan DT, Mitchell P, Sandar M et al. Prevalence of age-related macular degeneration in a Malay population: the Singapore Malay Eye Study. Ophthalmology 2008; 115(10): 1735-1741.

13 Kawasaki R, Yasuda M, Song SJ, Chen SJ, Jonas JB, Wang JJ et al. The prevalence of age-related macular degeneration in Asians: a systematic review and meta-analysis. Ophthalmology 117(5): 921-927.

14 Klein R, Klein BE, Knudtson MD, Wong TY, Cotch MF, Liu $\mathrm{K}$ et al. Prevalence of age-related macular degeneration in 4 racial/ethnic groups in the multi-ethnic study of atherosclerosis. Ophthalmology 2006; 113(3): 373-380.

15 Klein R, Davis MD, Magli YL, Segal P, Klein BE, Hubbard L. The Wisconsin age-related maculopathy grading system. Ophthalmology 1991; 98(7): 1128-1134.

16 Augood CA, Vingerling JR, de Jong PT, Chakravarthy U, Seland J, Soubrane G et al. Prevalence of age-related maculopathy in older Europeans: the European Eye Study (EUREYE). Arch Ophthalmol 2006; 124(4): 529-535.

17 Miyazaki M, Nakamura H, Kubo M, Kiyohara Y, Oshima Y, Ishibashi $\mathrm{T}$ et al. Risk factors for age related maculopathy in a Japanese population: the Hisayama study. Br J Ophthalmol 2003; 87(4): 469-472.

$18 \mathrm{Wu} Z \mathrm{ZQ}$. Epidemiologic survey of senile macular degeneration. Zhonghua Yan Ke Za Zhi 1992; 28(4): 246-247.

19 Vela C, Samson E, Zunzunegui MV, Haddad S, Aubin MJ, Freeman EE. Eye care utilization by older adults in low, middle, and high income countries. BMC Ophthalmol 2012; 12: 5 .

20 Vingerling JR, Dielemans I, Hofman A, Grobbee DE, Hijmering M, Kramer CF et al. The prevalence of age-related maculopathy in the Rotterdam Study. Ophthalmology 1995; 102(2): 205-210.

21 Cackett P, Wong TY, Aung T, Saw SM, Tay WT, Rochtchina E et al. Smoking, cardiovascular risk factors, and age-related macular degeneration in Asians: the Singapore Malay Eye Study. Am J Ophthalmol 2008; 146(6): 960-7 e1.

22 Friedman DS, Katz J, Bressler NM, Rahmani B, Tielsch JM. Racial differences in the prevalence of age-related macular degeneration: the Baltimore Eye Survey. Ophthalmology 1999; 106(6): 1049-1055.

23 Tomany SC, Cruickshanks KJ, Klein R, Klein BE, Knudtson MD. Sunlight and the 10-year incidence of age-related maculopathy: the Beaver Dam Eye Study. Arch Ophthalmol 2004; 122(5): 750-757.

24 Khan JC, Shahid H, Thurlby DA, Bradley M, Clayton DG, Moore AT et al. Age related macular degeneration and sun exposure, iris colour, and skin sensitivity to sunlight. Br J Ophthalmol 2006; 90(1): 29-32.

25 Fletcher AE, Bentham GC, Agnew M, Young IS, Augood C, Chakravarthy $\mathrm{U}$ et al. Sunlight exposure, antioxidants, and age-related macular degeneration. Arch Ophthalmol 2008; 126(10): 1396-1403.

26 Roberts JE. Ocular phototoxicity. J Photochem Photobiol B. 2001; 64(2-3): 136-143.

27 Lamb LE, Zareba M, Plakoudas SN, Sarna T, Simon JD. Retinyl palmitate and the blue-light-induced phototoxicity of human ocular lipofuscin. Arch Biochem Biophys 2001; 393(2): 316-320.

28 Delcourt C, Carriere I, Ponton-Sanchez A, Fourrey S, Lacroux A, Papoz L. Light exposure and the risk of age-related macular degeneration: the Pathologies Oculaires
Liees a l'Age (POLA) study. Arch Ophthalmol 2001; 119(10): 1463-1468.

29 Age-Related Eye Disease Study Research Group. A randomized, placebo-controlled, clinical trial of high-dose supplementation with vitamins $C$ and $E$, beta carotene, and zinc for age-related macular degeneration and vision loss: AREDS report no. 8. Arch Ophthalmol 2001; 119(10): 1417-1436.

30 Jampol LM. Antioxidants and zinc to prevent progression of age-related macular degeneration. JAMA 2001; 286(19): 2466-2468.

31 Tan JS, Wang JJ, Flood V, Rochtchina E, Smith W, Mitchell P. Dietary antioxidants and the long-term incidence of age-related macular degeneration: the Blue Mountains Eye Study. Ophthalmology 2008; 115(2): 334-341.

32 van Leeuwen R, Boekhoorn S, Vingerling JR, Witteman JC, Klaver CC, Hofman A et al. Dietary intake of antioxidants and risk of age-related macular degeneration. JAMA 2005; 294(24): 3101-3107.

33 Klein R, Klein BE, Tomany SC, Cruickshanks KJ. The association of cardiovascular disease with the long-term incidence of age-related maculopathy: the Beaver Dam eye study. Ophthalmology 2003; 110(4): 636-643.

34 Risk factors associated with age-related macular degeneration. A case-control study in the age-related eye disease study: Age-Related Eye Disease Study Report Number 3. Ophthalmology 2000; 107(12): 2224-2232.

35 van Leeuwen R, Ikram MK, Vingerling JR, Witteman JC, Hofman A. de Jong PT. Blood pressure, atherosclerosis, and the incidence of age-related maculopathy: the Rotterdam Study. Invest Ophthalmol Vis Sci 2003; 44(9): 3771-3777.

36 Sperduto RD, Hiller R. Systemic hypertension and age-related maculopathy in the Framingham Study. Arch Ophthalmol 1986; 104(2): 216-219.

37 Ciulla TA, Harris A, Kagemann L, Danis RP, Pratt LM, Chung HS et al. Choroidal perfusion perturbations in non-neovascular age related macular degeneration. Br J Ophthalmol 2002; 86(2): 209-213.

38 Vingerling JR, Dielemans I, Bots ML, Hofman A, Grobbee DE, de Jong PT. Age-related macular degeneration is associated with atherosclerosis. The Rotterdam Study. Am J Epidemiol 1995; 142(4): 404-409.

39 Sunlight + low antioxidant levels increase risk of AMD. Wear sunglasses and hats and eat antioxidant-rich foods to protect your eyes from age-related macular degeneration. Duke Med Health News 2009; 15(2): 6-7.

40 Seddon JM, Willett WC, Speizer FE, Hankinson SE. A prospective study of cigarette smoking and age-related macular degeneration in women. JAMA 1996; 276(14): 1141-1146.

41 Klein R, Peto T, Bird A, Vannewkirk MR. The epidemiology of age-related macular degeneration. Am J Ophthalmol 2004; 137(3): 486-495.

42 Smith W, Mitchell P, Leeder SR. Smoking and age-related maculopathy. The Blue Mountains Eye Study. Arch Ophthalmol 1996; 114(12): 1518-1523.

43 Xu L, Li Y, Zheng Y, Jonas JB. Associated factors for age related maculopathy in the adult population in China: the Beijing eye study. Br J Ophthalmol 2006; 90(9): 1087-1090.

44 Holz FG, Bindewald-Wittich A, Fleckenstein M, Dreyhaupt J, Scholl HP, Schmitz-Valckenberg S. Progression of geographic atrophy and impact of fundus autofluorescence patterns in age-related macular degeneration. Am J Ophthalmol 2007; 143(3): 463-472. 
45 Hall NF, Gale CR, Syddall H, Phillips DI, Martyn CN. Risk of macular degeneration in users of statins: cross sectional study. BMJ 2001; 323(7309): 375-376

46 Guymer RH, Chiu AW, Lim L, Baird PN. HMG CoA reductase inhibitors (statins): do they have a role in age-related macular degeneration? Surv Ophthalmol 2005; 50(2): 194-206
47 Kwok AK, Lai TY, Chan CW, Neoh EL, Lam DS. Polypoidal choroidal vasculopathy in Chinese patients. Br J Ophthalmol 2002; 86(8): 892-897.

48 Sho K, Takahashi K, Yamada H, Wada M, Nagai Y, Otsuji T et al. Polypoidal choroidal vasculopathy: incidence, demographic features, and clinical characteristics. Arch Ophthalmol 2003; 121(10): 1392-1396. 